SHEA Position Paper

\title{
Influenza Vaccination of Healthcare Workers and Vaccine Allocation for Healthcare Workers During Vaccine Shortages
}

\author{
Thomas R. Talbot, MD, MPH; Suzanne F. Bradley, MD; Sara E. Cosgrove, MD, MS; Christian Ruef, MD; \\ Jane D. Siegel, MD; David J. Weber, MD, MPH
}

\begin{abstract}
Influenza causes substantial morbidity and mortality annually, particularly in high-risk groups such as the elderly, young children, immunosuppressed individuals, and individuals with chronic illnesses. Healthcare-associated transmission of influenza contributes to this burden but is often under-recognized except in the setting of large outbreaks. The Centers for Disease Control and Prevention has recommended annual influenza vaccination for healthcare workers (HCWs) with direct patient contact since 1984 and for all HCWs since 1993 . The rationale for these recommendations is to reduce the chance that HCWs serve as vectors for healthcare-associated influenza due to their close contact with high-risk patients and to enhance both HCW and patient safety. Despite these recommendations as well as the effectiveness of interventions designed to increase $\mathrm{HCW}$ vaccination rates, the percentage of $\mathrm{HCWs}$

vaccinated annually remains unacceptably low. Ironically, at the same time that campaigns have sought to increase $\mathrm{HCW}$ vaccination rates, vaccine shortages, such as the shortage during the 2004-2005 influenza season, present challenges regarding allocation of available vaccine supplies to both patients and HCWs. This two-part document outlines the position of the Society for Healthcare Epidemiology of America on influenza vaccination for HCWs and provides guidance for the allocation of influenza vaccine to HCWs during a vaccine shortage based on influenza transmission routes and the essential need for a practical and adaptive strategy for allocation. These recommendations apply to all types of healthcare facilities, including acute care hospitals, long-term-care facilities, and ambulatory care settings (Infect Control Hosp Epidemiol 2005;26:882-890).
\end{abstract}

\section{PART I: INFLUENZA VACCINATION OF HEALTHCARE WORKERS (HCWS) Rationale}

Influenza infection causes an average of 36,000 excess deaths and nearly 226,000 excess hospitalizations annually in the United States alone. ${ }^{1,2}$ Contributing to this disease burden, influenza can be transmitted in healthcare settings from patient to patient, visitor to patient, patient to HCW, and HCW to patient. Healthcare-associated transmission of influenza has been documented in many different patient populations and clinical settings, including neonatal intensive care units, ${ }^{3-8}$ pediatric wards, ${ }^{9-12}$ adult and pediatric transplant units, ${ }^{13-16}$ infectious disease units, ${ }^{17,18}$ general medical wards, ${ }^{19-21}$ geriatric wards and long-term- care facilities, ${ }^{22-26}$ oncology units, ${ }^{27,28}$ pulmonary rehabilitation centers, ${ }^{29}$ and emergency departments. ${ }^{30}$ In many of these outbreaks, infections occurred in unvaccinated HCWs, and HCWs were linked epidemiologically to the transmission of influenza. Such healthcare-associated outbreaks of influenza may result in increased patient morbidity, mortality, length of hospitalization, and costs and may disrupt the essential services of a healthcare facility during a season when patient census and HCW absenteeism are high. ${ }^{19}$

Effective measures that can reduce the risk of healthcare-associated influenza during the influenza season include adherence to universal respiratory hygiene and cough etiquette practices, placement of patients with

Dr. Talbot is from the Departments of Medicine and Preventive Medicine, Vanderbilt University School of Medicine, Nashville, Tennessee. Dr. Bradley is from the Department of Internal Medicine, University of Michigan Medical School; and the Veterans Affairs Ann Arbor Healthcare System Ann Arbor, Michigan. Dr. Cosgrove is from the Department of Medicine, Johns Hopkins University School of Medicine, Baltimore, Maryland. Dr. Ruef is from the Division of Infectious Diseases and Hospital Epidemiology, Hospital Epidemiology Unit, University Hospital of Zurich, Zurich, Switzerland. Dr. Siegel is from the Department of Pediatrics, University of Texas Southwestern Medical Center, Dallas, Texas. Dr. Weber is from the Departments of Medicine and Pediatrics, University of North Carolina at Chapel Hill, Chapel Hill, North Carolina.

Address reprint requests to Thomas R. Talbot, MD, MPH, A-2200 Medical Center North, 1161 21st Avenue South, Vanderbilt University Medical Center, Nashville, TN 37232. tom.talbot@vanderbilt.edu

The authors thank Carolyn B. Bridges, MD; Denise M. Cardo, MD; Leonard A. Mermel, DO ScM. Trish M. Perl, MD, MSc; Gregory A. Poland, MD; William Schaffner, MD; Raymond A. Strikas, MD; Arjun Srinivasan, MD; and Michael L. Tapper, MD, for critical review of this manuscript. They also thank Annette Mucha for her assistance with this project.

This position paper was endorsed by the SHEA Board of Directors. 
influenza-like illness on droplet precautions at the point of first encounter, use of rapid diagnostic tests for patients and HCWs with suspected influenza, prompt treatment of patients with diagnosed influenza, provision of antiviral chemoprophylaxis for HCWs and patients under selected conditions, and restriction of ill HCWs from patient care. However, the cornerstone of efforts and the most effective measure to prevent healthcare-associated transmission of influenza is $\mathrm{HCW}$ vaccination with an effective influenza vaccine. $^{31}$

Influenza vaccination has been shown to reduce morbidity, antibiotic use, and absenteeism in healthy adults ${ }^{32,33}$ and to decrease serologically confirmed and clinical influenza, hospitalization for pneumonia and influenza, and mortality in the elderly. ${ }^{34}$ Influenza vaccination has also been effective in large studies specifically targeting HCWs (Fig. 1) ${ }^{35-39}$ Influenza vaccination reduces influenza infection in HCWs by $88 \%{ }^{39}$ and decreases work absence due to respiratory illness by $28 \%{ }^{38}$ In two separate studies in geriatric long-term-care facilities, total patient mortality was significantly lower in those sites where HCWs were routinely vaccinated as compared with sites where routine vaccination was not offered to HCWs (10\% vs $17 \%$ and $14 \%$ vs $22 \%) .{ }^{36,37}$ Increased rates of $\mathrm{HCW}$ vaccination also correspond to a significant decrease in the incidence of healthcare-associated influenza. ${ }^{40}$ Administration of influenza vaccine to healthy children of various ages has been shown to decrease morbidity and mortality in their close contacts and in their communities, further supporting the concept of immunizing HCWs to protect their high-risk contacts. ${ }^{41-45}$

Since 1984, the Advisory Committee on Immunization Practices of the Centers for Disease Control and Prevention (CDC) has strongly recommended annual influenza vaccination for HCWs to "protect [HCWs], their patients, and communities, [to] improve prevention of influenza-associated disease and patient safety, and [to] reduce disease burden." 31,46 Despite this recommendation, overall influenza vaccination rates in $\mathrm{HCW}$ s remain unacceptably low, with only $40 \%$ of HCWs having received an influenza vaccination in $2003 .{ }^{31}$ It has been suggested that vaccination of $80 \%$ of HCWs may be necessary to provide herd immunity to prevent healthcare-associated transmission of influenza. ${ }^{40,47}$

The rationale for influenza vaccination of $\mathrm{HCWs}$ is multifaceted: (1) to reduce influenza infection and illness in HCWs, (2) to reduce the risk of influenza transmission from an infected HCW to patients and other HCWs, (3) to decrease the absenteeism of essential HCWs due to influenza infection during community outbreaks when healthcare facilities are burdened, (4) to protect HCWs who have conditions that place them at high risk for influenza complications, and (5) to protect high-risk household and personal contacts of HCWs. These factors, coupled with low $\mathrm{HCW}$ vaccination rates, led the National Foundation for Infectious Diseases to stress the need to improve current $\mathrm{HCW}$ vaccination programs to protect HCWs and patients, a statement that was endorsed by more than 20 stakeholder orga-

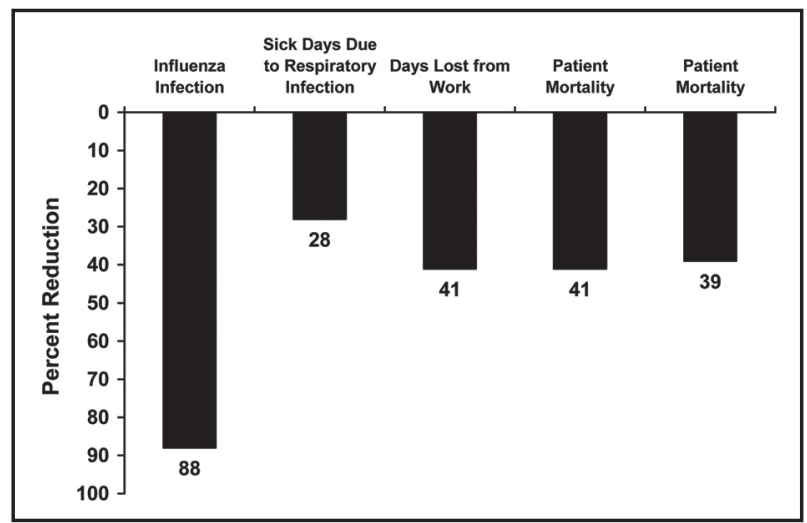

FIGURE 1. Percent of reduction in noted outcomes in healthcare workers receiving influenza vaccination. ${ }^{35-39}$ The two bars noting reductions in patient mortality data after healthcare worker vaccination reflect data from two separate studies. ${ }^{36,37}$ All values were statistically significant when compared with those for unvaccinated control healthcare workers $(P<.05)$.

nizations and professional associations. ${ }^{48}$ Additionally, multiple groups, including the Society for Healthcare Epidemiology of America (SHEA), the Association for Professionals in Infection Control and Epidemiology, and the CDC's Healthcare Infection Control Practices Advisory Committee, have included $\mathrm{HCW}$ influenza vaccination compliance as a potential measure for public reporting of rates of healthcare-associated infection in hospitals. ${ }^{49}$

\section{Barriers to HCW Acceptance of Influenza Vaccine}

Many studies have examined the reasons why HCWs fail to receive an annual influenza vaccination. Concerns about vaccine adverse effects (including fear of vaccine-induced illness), fear of injections, perceived lack of vaccine efficacy, busy schedules, inconvenience, failure of the employer to cover the cost of vaccine, and opposition to vaccination in general have all been noted in surveys of unvaccinated HCWs (Table 1)..$^{50-62}$ In addition, healthy HCWs often do not recognize their role in influenza transmission to their patients or their families, seeing themselves at low risk for influenza infection and subsequent morbidity. ${ }^{57}$ Reasons for declining annual influenza vaccination may also differ by provider job category or setting, signaling a need to tailor educational interventions. ${ }^{52,53,58}$

Another concern is the self-reported percentage of HCWs who work while ill with an influenza-like illness, reaching $76.6 \%$ in one study. ${ }^{53}$ In another study, $36.7 \%$ of housestaff self-reported the development of an influenzalike illness during the influenza season and worked a mean of 2.5 days while ill. ${ }^{55} \mathrm{HCWs}$, as with other healthy adults, may have minimal or no symptoms during their influenza infection but still shed the virus, thus potentially exposing their patients and colleagues. ${ }^{63}$ One study during a mild influenza epidemic noted that $28 \%$ of HCWs with serologically confirmed influenza infection during the influenza season 
TABLE 1

BARRIERS TO HEALTHCARE WORKER INFLUENZA VACCINATION AND RECOMMENDED COMPONENTS OF HEALTHCARE WORKER INFLUENZA VACCINATION PROGRAMS

\begin{tabular}{ll}
\hline Barrier to HCW Influenza Vaccination & \multicolumn{1}{c}{ Recommended Component of HCW Influenza Vaccination Program } \\
\hline Access to vaccine, inconvenience & Off-hours clinics \\
& Use of mobile vaccination carts \\
& Vaccination at staff and departmental meetings \\
& Provision of adequate staff and resources \\
& Provision of vaccine free of charge to HCWs \\
Cost & Targeted education, including specific information to dispel vaccine myths \\
Concerns for vaccine adverse events, perception of low & \\
risk for influenza, opposition to the vaccine & Use of live attenuated influenza vaccine for eligible HCWs \\
Fear of needles & Strong and visible administrative leadership \\
& Visible vaccination of key leaders \\
& Active declination for HCWs who do not wish to be or cannot be vaccinated \\
& Accurate tracking of individual and unit-based compliance of HCWs with vaccination \\
& Surveillance for healthcare-associated influenza \\
\hline
\end{tabular}

$\mathrm{HCW}=$ healthcare worker.

could not recall having any respiratory infection during that period. ${ }^{64}$

\section{Comprehensive Strategy Recommended by SHEA}

Because influenza vaccination is effective in reducing the transmission of influenza virus and the burden of disease, has minimal adverse effects when compared with a placebo in randomized trials, and can have a dramatic impact on the safety of HCWs and their patients, SHEA continues to endorse the National Foundation for Infectious Diseases' call to action ${ }^{48}$ and strongly recommends that active efforts be made to improve $\mathrm{HCW}$ vaccination rates. Therefore, we provide recommendations for a multifaceted program aimed at providing targeted education, increasing vaccine access, and emphasizing the ethical responsibility HCWs have to protect themselves, their patients, and their colleagues as part of institutional patient and employee safety programs. These recommendations apply to all types of healthcare facilities, including acute care hospitals, long-term-care facilities, and ambulatory care settings, including free-standing clinics, outpatient surgery and dialysis centers, physicians' offices, and home care agencies.

We propose that an effective program to increase $\mathrm{HCW}$ vaccination rates must (1) provide targeted education annually to all HCWs about the severity of influenza, particularly among high-risk patients, and the safety of influenza vaccination; (2) inform HCWs of the importance of influenza vaccination in promoting patient and employee safety; (3) provide vaccine at no cost and at convenient locations and times; (4) recommend that HCW sign a declination each year if they refuse influenza vaccination after participating in an educational program or if they have medical contraindications to the vaccine (Fig. 2) ${ }^{65}$; and (5) perform surveillance of rates of vaccine uptake by medical unit as well as identification of patients with healthcare-associated influenza to assess the impact of the vaccination program.

The educational component of any $\mathrm{HCW}$ vaccination program must explain the rationale for vaccination of $\mathrm{HCWs}$ and provide specific messages directed at dispelling myths about influenza vaccination, such as the perceived risk of post-vaccination influenza-like illness that has not been substantiated by clinical trials. ${ }^{32,33,38}$ Vaccination should be convenient and easily accessible to minimize the impact on the daily activities and duties of HCWs. Proven tools such as the use of mobile vaccination carts, continuous educational campaigns, visible vaccination of key leaders, off-hours clinics, incentives, and targeted vaccination at departmental or staff meeting $\mathrm{s}^{40,66-72}$ should all be considered as part of a facility's influenza vaccination program (Table 1$)$. In addition, influenza vaccine should be provided free of charge by the healthcare facility, as is done with other occupational safety measures.

Although the use of active declination to increase influenza vaccination rates has not been tested specifically, it is currently a component of HCW hepatitis B vaccination programs as required by the Occupational Safety \& Health Administration's Bloodborne Pathogens and Needlestick Prevention standard. ${ }^{65}$ As a result of enhanced vaccination programs that include active declination and the implementation of standard precautions, $\mathrm{HCW}$ vaccination rates have increased and healthcareassociated hepatitis B infection rates in HCWs have decreased by $98 \%{ }^{73}$ Active declination of influenza vaccination as a part of a $\mathrm{HCW}$ vaccination program is also one of the 30 measured safe practices in the Leapfrog Hospital Quality and Safety Survey. ${ }^{74}$ In addition, multiple states 
have proposed legislation mandating influenza vaccination of HCWs in long-term-care facilities and acute care hospitals. ${ }^{75}$

A recommendation for active declination as a part of influenza vaccination programs will result in increased workload and recordkeeping for infection control and occupational health staff. The annual nature of influenza vaccination campaigns, which occur within a few targeted weeks each fall, also provides additional challenges; however, other types of annual HCW screening may be used as models for influenza vaccination campaigns for HCWs. Healthcare facility administrators must provide ample financial support and human resources to ensure the success of their program, which may require seasonal hires of information technology, secretarial, and nursing personnel to accommodate the demands of the annual vaccination campaign. Active declination of the vaccine must also be coupled with the other interventions noted above designed to increase access to and ease of vaccination. During a vaccine shortage, active declination programs should be directed only at those HCWs targeted to receive vaccine through the facility's allocation plan based on the intensity and duration of contact with patients (see Part II below).

A facility must also be aware of and record influenza vaccination of HCWs from sources other than the facility-based vaccination program, such as the HCWs' personal medical provider or alternative employment site. In some employment settings, the proportion of $\mathrm{HCW}$ receiving vaccination through alternative venues may be substantial. A study of medical residents found that $64 \%$ of housestaff noted as unvaccinated by the facility's formal program had actually been vaccinated at other sites. ${ }^{76}$ Offering the vaccine free of charge to all HCWs and providing convenient access to the vaccine may reduce such off-site vaccination practices. However, written documentation of off-site receipt of vaccine is acceptable. In addition, strategies such as real-time data entry may allow facilities to monitor the week-by-week uptake of vaccine and the subsequent targeting of units with a low rate of compliance.

Facilities should also conduct routine surveillance for healthcare-associated influenza to assess the impact of the $\mathrm{HCW}$ vaccination program. As cases of healthcare-associated influenza may be unrecognized unless they are part of a larger unit- or facility-wide outbreak, prospective surveillance has been used at some facilities and has been effective in detecting smaller outbreaks of infection. ${ }^{40,77}$ The degree of surveillance, definitions for influenza-like illness, and the need for laboratory confirmation of influenza, however, may depend on the size and available resources of the facility. Other measures of the impact of a $\mathrm{HCW}$ vaccination program are less reliable. For example, tracking reports of influenza-like illness in HCWs is difficult to perform accurately and monitoring absenteeism may underestimate vaccine effect given the high reported percentage of HCWs who work while ill. ${ }^{55}$ In addition, because the majority of influenza-like illness is not influenza,

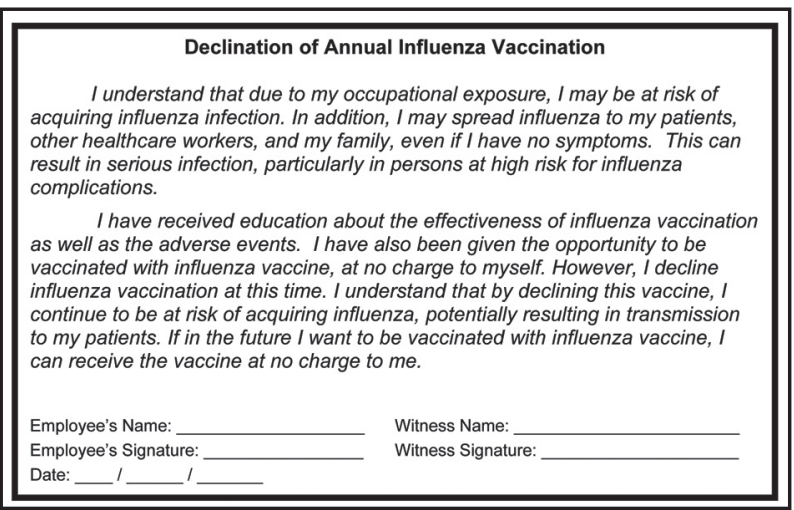

FIGURE 2. Example of an active declination form for healthcare worker influenza vaccination programs (adapted from Appendix A of the Occupational Safety \& Health Administration's Bloodborne Pathogens and Needlestick Prevention ${ }^{65}$ ).

tracking influenza-like illness alone is likely to mask the benefits of vaccination.

\section{Summary Recommendations for HCW Influenza Vaccination}

1. For the safety of HCWs and patients, all HCWs should receive influenza vaccine annually unless they have a contraindication to the vaccine or actively decline vaccination.

2. All healthcare facilities should provide annual multifaceted programs to actively promote vaccination of HCWs.

3. Influenza vaccination programs should contain the following elements:

a. Targeted education about the severity of influenza illness, particularly in high-risk patients.

b. Targeted education about vaccine efficacy and safety as well as dispelling of vaccine myths.

c. Administrative support and leadership.

d. Provision of vaccine at no cost to HCWs.

e. Improved access to vaccine (eg, via mobile carts and off-hours clinics).

f. Active declination policy for HCWs who do not want or cannot receive influenza vaccine.

4. All healthcare facilities should accurately track and record $\mathrm{HCW}$ vaccination rates, including vaccinations obtained outside of the formal facility program, to assess the effectiveness of the vaccine program. These data should include compliance for individual HCWs and unit-specific rates.

5. Each facility should have a surveillance system for healthcare-associated influenza to assess the impact of its vaccination program.

\section{PART II: ALLOCATION OF INFLUENZA VACCINE TO HCWS DURING A SHORTAGE}

In the fall of 2004 , the license of one of the two main manufacturers of inactivated trivalent influenza vac- 
cine was suspended in the United States, resulting in a widespread vaccine shortage. The CDC recommended prioritized delivery of available vaccine to those at greatest risk for influenza complications as well as to HCWs caring for these individuals. ${ }^{78}$ Delivery of vaccine in 2004-2005 was sporadic, with some areas reporting a vaccine surplus at the end of the influenza season. Although the total number and timing of distribution of available doses for the 2005-2006 season is currently unknown, the CDC anticipates that four manufacturers will supply influenza vaccine (three that produce trivalent influenza vaccine and one that produces the live attenuated vaccine).$^{79,80}$ However, a potential shortage of influenza vaccine in Europe for the coming season has already been reported. ${ }^{81}$

As disruptions in the manufacture or distribution of inactivated influenza vaccine have occurred in three of the past five seasons in the United States, ${ }^{78,79,82}$ guidance is required about allocation of available vaccine to HCWs during a delay or shortage of vaccine. Detailed recommendations for allocation of influenza vaccine to patients during a vaccine shortage have been published, but no stratification within the group of HCWs was included. ${ }^{79}$

Developing guidance on vaccine allocation to HCWs is a challenging task, as one specific strategy may not be feasible for all healthcare facilities. For any healthcare facility, protection of patients and having sufficient numbers of HCWs to care directly for those patients is a primary goal. Allocation criteria should be evidence based and adhere to the key ethical principles of nonmaleficence (avoiding the causation of harm), beneficence (providing benefits and balancing benefits against risk and costs), and justice (the fair distribution of benefits, risks, and costs). ${ }^{83}$ Whereas the decisions of healthcare providers are often focused on a single patient, decisions regarding allocation of scarce resources such as influenza vaccine must focus on the well-being of the population. Furthermore, any allocation strategy must be practical, transparent to engender trust and allow HCWs to understand the rationale for allocation, and prompt in delivering available vaccine to HCWs.

In addition, vaccine allocation strategies must also consider several key factors:

Routes of Influenza Transmission. Although airborne transmission of influenza has been suspected in animal and observational studies and may occur under specific conditions of confined air spaces with suboptimal air circulation, ${ }^{84-86}$ the predominant route of transmission of influenza virus is thought to be via large respiratory droplets $(>10 \mu \mathrm{m})$ that may be propelled a short distance (up to 3 feet) by sneezing or coughing but that do not remain suspended in the air. ${ }^{87,88}$ Influenza transmission has been prevented by using droplet precautions. ${ }^{89}$ Thus, prioritizing vaccination for HCWs according to the nature, degree, and duration of patient contact may be necessary during a vaccine shortage. Prioritizing those HCWs with close (within 3 feet), prolonged (several minutes), and repeated patient contact would target those most at risk of exposure to and transmission of influenza, potentially maximizing the impact of HCW vaccination with a limited vaccine supply.

Degree of HCW Contact With Patients at High Risk for Influenza Complications. Although all unvaccinated patients are at risk of contracting influenza from an infected HCW, during a severe vaccine shortage it may be necessary to allocate vaccine to those $\mathrm{HCW}$ sho have the most frequent and intense contact with patients at greatest risk for complications and adverse outcomes.

Need to Cover Essential HCWs and Services. Certain functions and services of a healthcare facility are vital for the care of patients, the health of the community, and the functioning of the institution. HCWs performing such services may be prioritized for vaccination to prevent disruption of these services. For example, the only level-1 trauma center in a community would need to ensure available trauma services and, therefore, may place essential trauma staff high on the priority list for vaccination.

Exposure Risk in Areas of High Patient Traf-

fic in a Facility. Areas with a large volume of patients not yet identified as having influenza (such as emergency departments, high-volume acute care clinics, and active units with high occupancy and rapid patient turnover) can increase the risk of HCW exposure to infectious patients and the subsequent transmission to a larger number of patients. Vaccinating HCWs in these high traffic areas may also provide the largest impact with available vaccine supplies.

Areas Where Infected Patients Are Less Likely to Be Properly and Promptly Isolated. HCWs in areas where exposure to patients with influenza can occur before these patients can be placed on droplet precautions, such as emergency department staff, acute care clinic employees, and emergency first responders, may be at greater risk of contracting influenza as opposed to HCWs in units where patients with influenza are more likely to be isolated prior to exposure.

Use of the Live Attenuated Influenza Vaccine in Eligible $\mathbf{H C W s}$. An important alternative to the inactivated trivalent influenza vaccine is the live attenuated influenza vaccine, which is licensed for use in healthy individuals 5 to 49 years old. A theoretical concern about the use of live attenuated influenza vaccine has been the possibility for secondary transmission of the vaccine virus; however, the live attenuated influenza vaccine virus is modified to limit growth in temperatures higher than $37^{\circ} \mathrm{C}$ (similar to the temperature of the lower airways). Therefore, it is unlikely that the vaccine virus would survive or replicate in the airways. The vaccine virus has also been modified into a nonvirulent strain that cannot cause disease in the event of inadvertent transmission. ${ }^{90}$ For effective transmission of live attenuated influenza vaccine virus to a vulnerable patient, the recipient must shed the virus in a large enough quantity, the shed virus must lose its inability to replicate at higher temperatures, and the virus must revert back to the wild 
type and produce disease. ${ }^{91}$ This chain of events is exceedingly unlikely based on virologic data from individuals who received live attenuated influenza vaccine. ${ }^{91-93}$ The quantity of virus shed in recently vaccinated individuals is well below the known infective dose of influenza virus, ${ }^{92}$ genetic reversion to the virulent wild type virus has never been noted, and, despite an increasing use of live attenuated influenza vaccine, transmission of vaccine virus has been reported in only one individual, who had no symptoms. ${ }^{94}$

To allocate limited supplies of inactivated trivalent influenza vaccine during a shortage, use of live attenuated influenza vaccine in selected HCWs is prudent, thus saving trivalent influenza vaccine for those who cannot receive live attenuated influenza vaccine due to comorbid illness or work in a restricted unit. Due to the theoretical risk of transmission of live virus, the CDC advises that HCWs who receive live attenuated influenza vaccine avoid contact with severely immunosuppressed patients who require care in a protective environment (eg, hematopoietic stem cell transplant recipients hospitalized in a room with positive airflow such as in a myelosuppression or bone marrow transplant unit) for only 7 days after vaccination because shedding of virus has not been detected in adults after this time. ${ }^{31,92,95}$

Use of Non-Vaccine Measures to Prevent Influenza. During any influenza season, measures other than vaccination are also important to reduce the risk of healthcare-associated transmission of influenza. However, during a vaccine shortage, these measures become even more essential for the protection of HCWs and patients. These measures include adhering to hand hygiene practices, using respiratory hygiene and cough etiquette (ie, use of a surgical mask and placement of patients with respiratory symptoms at least 3 feet apart from other patients in the waiting room, use of tissues to contain nasal secretions, and use of an alcohol-based hand hygiene agent after hand contamination with nasal secretions), ${ }^{96}$ and screening of visitors to high-risk patient areas (eg, intensive care or oncology units) with exclusion of sick visitors from the facility. ${ }^{95} \mathrm{HCW}$ s with a febrile respiratory illness should be placed on sick leave. Afebrile HCWs with acute respiratory symptoms consistent with a viral infection should be excluded from contact with patients at the highest risk. However, if they are able to contain their respiratory secretions and control coughing, the use of a surgical mask and consistent hand hygiene adherence while performing patient care activities will reduce the risk of transmission. Antiviral chemoprophylaxis may also be used to prevent infection in individuals at risk during community or facility outbreaks. ${ }^{31}$

Methods to Increase the Available Supply of Inactivated Trivalent Influenza Vaccine. Other options to increase the available inactivated influenza vaccine supply have been examined and are promising, such as intradermal injection of trivalent influenza vaccine and reducing the dose for intramuscular administration in otherwise healthy young adults. ${ }^{97-99}$ However, further data are needed before making firm recommendations based on these strategies.
HCWs Who Are Not in a Priority Group During a Vaccine Shortage. This group of HCWs should receive information about non-vaccine strategies for the prevention of influenza as well as community-based sites where vaccine might be available. HCWs who have not been placed in a priority subgroup for receiving vaccine during a shortage (eg, direct patient care) but have been included in a CDC-defined patient risk group by virtue of age, pregnancy, or an underlying illness should be encouraged to obtain vaccine via their local healthcare provider or local health department. A process should also be developed to rapidly inform unvaccinated $\mathrm{HCW}$ s as priorities change and vaccine becomes available so that they can be expeditiously vaccinated. If vaccine supply is adequate at the local facility, vaccination at the facility's occupational health service is appropriate.

Flexibility to Address the Unique Needs of a Facility. Because every healthcare facility has unique needs, services, and idiosyncrasies, any $\mathrm{HCW}$ vaccine allocation strategy must be adaptive to fit to the local needs of the institution. A multidisciplinary facility advisory board composed of institutional leaders in key areas (eg, infectious diseases, occupational medicine, infection control, pediatrics, geriatrics, pharmacy; the institutional ethics committee; and administration) may be helpful to determine the facility's high-risk areas and populations as well as to allocate vaccine supplies as they become available. Facilities may also develop novel tools to assist in vaccine allocation. During the 2004-2005 shortage, one institution required $\mathrm{HCW}$ s to complete a facility-specific questionnaire that used influenza risk factors, Occupational Safety \& Health Administration respirator medical screening, and an assessment of the degree of patient contact to devise an index score that was used to determine vaccine delivery. This resulted in a vaccination rate higher than historical averages. ${ }^{100}$

\section{A Proposed Tiered Approach to Vaccine Allocation}

Using the recommendations noted above, we propose a tiered distribution of influenza vaccine for HCWs in the event of inadequate supply. The highest priority should be given to HCWs with the greatest risk of exposure to the patients at highest risk for influenza complications (Table 2). During a vaccine shortage, HCWs who have close (within 3 feet), prolonged (several minutes), and repeated contact with the patients at the highest risk comprise the first tier (1A). For example, a specific facility may elect to vaccinate intensive care unit nurses and respiratory therapists before other staff who have a lesser degree of close patient contact to maximize the benefits from a limited vaccine supply. As vaccine supplies increase, other HCWs working with high-risk patients, essential HCWs, and HCWs in areas of high patient traffic should be vaccinated (tiers $1 B$ and $1 C$ ). With larger supplies, all HCWs with patient care responsibilities should receive the vaccine (tier 2 ). To protect HCWs who are not vaccinated, as well as those who are, and 
TABLE 2

TIERED ALLOCATION FOR VACCINATION OF HEALTHCARE WORKERS IN TIMES OF INFLUENZA VACCINE SHORTAGE

\begin{tabular}{ll}
\hline Tier & \multicolumn{1}{c}{ Description } \\
\hline $1 A^{*}$ & $\begin{array}{l}\text { HCWs in close (within 3 feet), prolonged, and repeated contact with high-risk patients in high-risk units (eg, ICU, emer- } \\
\text { gency department, myelosuppression or transplant unit, obstetrics ward, newborn nursery, general pediatric and medical } \\
\text { wards, and long-term-care facility) }\end{array}$ \\
AB & $\begin{array}{l}\text { All HCWs in close but not prolonged or repeated contact with high-risk patients in high-risk units } \\
\text { 1C }\end{array}$ \\
& HCWs in units with high patient traffic \\
2 & HCWs who perform essential patient care functions within the institution \\
3 & All other HCWs \\
\hline HCW = healthcare worker; ICU = intensive care unit. \\
${ }^{*}$ Consider all groups in tier 1 equal except during times of severe vaccine shortage.
\end{tabular}

their patients, other strategies to reduce transmission should also be actively promoted and used. It must be acknowledged that during a severe vaccine shortage, available supplies may not be sufficient to cover every HCW in the highest priority group. Facility leaders, together with a multidisciplinary advisory panel, must base their decisions for vaccine allotment on the principles outlined above with clear communication of the rationale to all HCWs in the organization. This process must be applied uniformly and must be transparent, with the rationale for allocation decisions readily apparent. Finally, this tiered system should be applied only in the event of a vaccine shortage; during non-shortage periods, facilities should follow the $\mathrm{CDC}$ recommendations and offer influenza vaccine to all HCWs. ${ }^{31}$

\section{Summary Recommendations for the Allocation of Vaccine During a Shortage}

1. Vaccine allocation strategies must focus primarily on the protection of patients at highest risk for complications from influenza.

2. Allocation strategies must use data on influenza transmission risk to identify those HCWs at greatest risk of transmitting influenza to high-risk patients.

3. During times of limited supply, the tiered strategy presented in Table 2 should be followed.

4. Live attenuated influenza vaccine should be used in eligible $\mathrm{HCW}$ s to conserve trivalent influenza vaccine supplies.

5. As during times when vaccine supplies are ample, healthcare facilities should continue to emphasize non-vaccine measures (infection control precautions, respiratory hygiene and cough etiquette, and chemoprophylaxis) for the prevention of transmission of influenza, as well as other respiratory viruses, among HCWs and patients.

\section{CONCLUSIONS}

As outlined above, vaccination of HCWs is a key measure in the prevention of healthcare-associated influenza. $\mathrm{HCW}$ vaccination programs must be multifaceted, evidence driven, and focused on maximizing the effect of available vaccine from a population standpoint. Although allocation decisions during a vaccine shortage can be challenging, using principles of influenza transmission, identifying the unique needs of a facility, and applying effective, non-vaccine interventions can optimize the impact of a $\mathrm{HCW}$ vaccination program.

\section{REFERENCES}

1. Thompson WW, Shay DK, Weintraub E, et al. Mortality associated with influenza and respiratory syncytial virus in the United States. JAMA 2003;289:179-186.

2. Thompson WW, Shay DK, Weintraub E, et al. Influenza-associated hospitalizations in the United States. JAMA 2004;292:1333-1340.

3. Munoz FM, Campbell JR, Atmar RL, et al. Influenza A virus outbreak in a neonatal intensive care unit. Pediatr Infect Dis J 1999;18:811-815.

4. Meibalane R, Sedmak GV, Sasidharan P, Garg P, Grausz JP. Outbreak of influenza in a neonatal intensive care unit. J Pediatr 1977;91:974-976.

5. Bauer CR, Elie K, Spence L, Stern L. Hong Kong influenza in a neonatal unit. JAMA 1973;223:1233-1235.

6. Cunney RJ, Bialachowski A, Thornley D, Smaill FM, Pennie RA. An outbreak of influenza A in a neonatal intensive care unit. Infect Control Hosp Epidemiol 2000;21:449-454.

7. Sagrera X, Ginovart G, Raspall F, et al. Outbreaks of influenza A virus infection in neonatal intensive care units. Pediatr Infect Dis J 2002:21:196-200.

8. Maltezou HC, Drancourt M. Nosocomial influenza in children. J Hosp Infect 2003;55:83-91.

9. Serwint JR, Miller RM, Korsch BM. Influenza type A and B infections in hospitalized pediatric patients: who should be immunized? $\mathrm{Am} \mathrm{J}$ Dis Child 1991;145:623-626.

10. Slinger R, Dennis P. Nosocomial influenza at a Canadian pediatric hospital from 1995 to 1999: opportunities for prevention. Infect Con trol Hosp Epidemiol 2002;23:627-629.

11. Hall CB, Douglas RG Jr. Nosocomial influenza infection as a cause of intercurrent fevers in infants. Pediatrics 1975;55:673-677.

12. Wenzel RP, Deal EC, Hendley JO. Hospital-acquired viral respiratory illness on a pediatric ward. Pediatrics 1977;60:367-371.

13. Mauch TJ, Bratton S, Myers T, Krane E, Gentry SR, Kashtan CE. Influenza $B$ virus infection in pediatric solid organ transplant recipients. Pediatrics 1994;94:225-229.

14. Weinstock DM, Eagan J, Malak SA, et al. Control of influenza A on a bone marrow transplant unit. Infect Control Hosp Epidemiol 2000;21:730-732.

15. Whimbey E, Elting LS, Couch RB, et al. Influenza A virus infections among hospitalized adult bone marrow transplant recipients. Bone Marrow Transplant 1994;13:437-440.

16. Malavaud S, Malavaud B, Sandres K, et al. Nosocomial outbreak of influenza virus A (H3N2) infection in a solid organ transplant department. Transplantation 2001;72:535-537.

17. Horcajada JP, Pumarola T, Martinez JA, et al. A nosocomial outbreak of influenza during a period without influenza epidemic activity. Eur Respir J 2003;21:303-307. 
18. Barlow G, NathwaniD. Nosocomialinfluenzainfection.Lancet2000;355: 1187.

19. Sartor C, Zandotti C, Romain F, et al. Disruption of services in an internal medicine unit due to a nosocomial influenza outbreak. Infect Control Hosp Epidemiol 2002;23:615-619.

20. Van Voris LP, Belshe RB, Shaffer JL. Nosocomial influenza B virus infection in the elderly. Ann Intern Med 1982;96:153-158.

21. Bean B, Rhame FS, Hughes RS, Weiler MD, Peterson LR, Gerding DN. Influenza B: hospital activity during a community epidemic. Diagn Microbiol Infect Dis 1983;1:177-183.

22. Morens DM, Rash VM. Lessons from a nursing home outbreak of influenza A. Infect Control Hosp Epidemiol 1995;16:275-280.

23. Nabeshima A, Ikematsu H, Yamaga S, Hayashi J, Hara H, Kashiwagi S. An outbreak of influenza A (H3N2) among hospitalized geriatric patients [in Japanese]. Kansenshogaku Zasshi 1996;70:801-807.

24. Everts RJ, Hanger HC, Jennings LC, Hawkins A, Sainsbury R. Outbreaks of influenza A among elderly hospital inpatients. $N Z \mathrm{Med} J$ 1996;109:272-274.

25. Staynor K, Foster G, McArthur M, McGeer A, Petric M, Simor AE. Influenza A outbreak in a nursing home: the value of early diagnosis and the use of amantadine hydrochloride. Can J Infect Control 1994;9:109-111.

26. Drinka PJ, Gravenstein S, Krause P, Nest L, Dissing M, Shult P. Reintroduction of influenza A to a nursing building. Infect Control Hosp Epidemiol 2000;21:732-735.

27. Kempe A, Hall CB, MacDonald NE, et al. Influenza in children with cancer. J Pediatr 1989;115:33-39.

28. Schepetiuk S, Papanaoum K, Qiao M. Spread of influenza A virus infection in hospitalised patients with cancer. Aust N Z J Med 1998;28:475476.

29. Berg HF, Van Gendt J, Rimmelzwaan GF, Peeters MF, Van Keulen P. Nosocomial influenza infection among post-influenza-vaccinated patients with severe pulmonary diseases. J Infect 2003;46:129-132.

30. Weingarten S, Friedlander M, Rascon D, Ault M, Morgan M, Meyer RD. Influenza surveillance in an acute-care hospital. Arch Intern Med 1988;148:113-116.

31. Harper SA, Fukuda K, Uyeki TM, Cox NJ, Bridges CB. Prevention and control of influenza: recommendations of the Advisory Committee on Immunization Practices (ACIP). MMWR Recomm Rep 2005;54:1-40.

32. Nichol KL, Lind A, Margolis KL, et al. The effectiveness of vaccination against influenza in healthy, working adults. $N \mathrm{Engl} \mathrm{J} \mathrm{Med}$ 1995;333:889-893.

33. Bridges CB, Thompson WW, Meltzer MI, et al. Effectiveness and cost-benefit of influenza vaccination of healthy working adults: a randomized controlled trial. JAMA 2000;284:1655-1663.

34. Govaert TM, Thijs CT, Masurel N, Sprenger MJ, Dinant GJ, Knottnerus JA. The efficacy of influenza vaccination in elderly individuals: a randomized double-blind placebo-controlled trial. JAMA 1994;272:1661-1665

35. Feery BJ, Evered MG, Morrison EI. Different protection rates in various groups of volunteers given subunit influenza virus vaccine in 1976. J Infect Dis 1979;139:237-241.

36. Carman WF, Elder AG, Wallace LA, et al. Effects of influenza vaccination of health-care workers on mortality of elderly people in long-term care: a randomised controlled trial. Lancet 2000;355:93-97.

37. Potter J, Stott DJ, Roberts MA, et al. Influenza vaccination of health care workers in long-term-care hospitals reduces the mortality of elderly patients. J Infect Dis 1997;175:1-6.

38. Saxen H, Virtanen M. Randomized, placebo-controlled double blind study on the efficacy of influenza immunization on absenteeism of health care workers. Pediatr Infect Dis J 1999;18:779-783.

39. Wilde JA, McMillan JA, Serwint J, Butta J, O'Riordan MA, Steinhoff MC. Effectiveness of influenza vaccine in health care professionals: a randomized trial. JAMA 1999;281:908-913.

40. Salgado CD, Giannetta ET, Hayden FG, Farr BM. Preventing nosocomial influenza by improving the vaccine acceptance rate of clinicians. Infect Control Hosp Epidemiol 2004;25:923-928.

41. Monto AS, Davenport FM, Napier JA, Francis T Jr. Modification of an outbreak of influenza in Tecumseh, Michigan by vaccination of schoolchildren. J Infect Dis 1970;122:16-25.

42. Reichert TA, Sugaya N, Fedson DS, Glezen WP, Simonsen L, Tashiro $\mathrm{M}$. The Japanese experience with vaccinating schoolchildren against influenza. N Engl J Med 2001;344:889-896.

43. Longini IM Jr, Halloran ME. Strategy for distribution of influenza vaccine to high-risk groups and children. Am J Epidemiol 2005;161:303306.

44. Piedra PA, Gaglani MJ, Kozinetz CA, et al. Herd immunity in adults against influenza-related illnesses with use of the trivalent-live attenuated influenza vaccine (CAIV-T) in children. Vaccine 2005;23:15401548 .
45. Hurwitz ES, Haber M, Chang A, et al. Effectiveness of influenza vaccination of day care children in reducing influenza-related morbidity among household contacts. JAMA 2000;284:1677-1682.

46. Department of Health and Human Services. Prevention and control of influenza: recommendation of the Immunization Practices Advisory Committee, Centers for Disease Control. Ann Intern Med 1984;101:218-222.

47. Recommendations for prevention and control of influenza. Recommendations of the Immunization Practices Advisory Committee. Centers for Disease Control, Department of Health and Human Services. Ann Intern Med 1986;105:399-404.

48. National Foundation for Infectious Diseases. Improving Influenza Vaccination Rates in Healthcare Workers: Strategies to Increase Protection for Workers and Patients. Bethesda, MD: National Foundation for Infectious Diseases; 2004. Available at www.nfid.org. Accessed September 2, 2005

49. McKibben L, Horan T, Tokars JI, et al. Guidance on public reporting of healthcare-associated infections: recommendations of the Healthcare Infection Control Practices Advisory Committee. Am J Infect Control 2005;33:217-226.

50. Manuel DG, Henry B, Hockin J, Naus M. Health behavior associated with influenza vaccination among healthcare workers in long-termcare facilities. Infect Control Hosp Epidemiol 2002;23:609-614.

51. Steiner M, Vermeulen LC, Mullahy J, Hayney MS. Factors influencing decisions regarding influenza vaccination and treatment: a survey of healthcare workers. Infect Control Hosp Epidemiol 2002;23:625-627.

52. Ballada D, Biasio LR, Cascio G, et al. Attitudes and behavior of health care personnel regarding influenza vaccination. Eur J Epidemiol 1994;10:63-68.

53. Weingarten S, Riedinger M, Bolton LB, Miles P, Ault M. Barriers to influenza vaccine acceptance: a survey of physicians and nurses. Am J Infect Control 1989;17:202-207.

54. LaVela SL, Smith B, Weaver FM, Legro MW, Goldstein B, Nichol $\mathrm{K}$. Attitudes and practices regarding influenza vaccination among healthcare workers providing services to individuals with spinal cord injuries and disorders. Infect Control Hosp Epidemiol 2004;25:933940.

55. Lester RT, McGeer A, Tomlinson G, Detsky AS. Use of, effectiveness of, and attitudes regarding influenza vaccine among house staff. Infect Control Hosp Epidemiol 2003;24:839-844

56. Beguin C, Boland B, Ninane J. Health care workers: vectors of influenza virus? Low vaccination rate among hospital health care workers. Am J Med Qual 1998;13:223-227.

57. Nichol KL, Hauge M. Influenza vaccination of healthcare workers Infect Control Hosp Epidemiol 1997;18:189-194.

58. Martinello RA, Jones L, Topal JE. Correlation between healthcare workers' knowledge of influenza vaccine and vaccine receipt. Infect Control Hosp Epidemiol 2003;24:845-847.

59. Smedley J, Palmer C, Baird J, Barker M. A survey of the delivery and uptake of influenza vaccine among health care workers. Occup Med (Lond) 2002;52:271-276.

60. Heimberger T, Chang HG, Shaikh M, Crotty L, Morse D, Birkhead G. Knowledge and attitudes of healthcare workers about influenza: why are they not getting vaccinated? Infect Control Hosp Epidemiol 1995;16:412-415.

61. Qureshi AM, Hughes NJ, Murphy E, Primrose WR. Factors influencing uptake of influenza vaccination among hospital-based health care workers. Occup Med (Lond) 2004;54:197-201.

62. Mah MW, Hagen NA, Pauling-Shepard K, et al. Understanding influenza vaccination attitudes at a Canadian cancer center. Am I Infect Control 2005;33:243-250.

63. Foy HM, Cooney MK, Allan ID, Albrecht JK. Influenza B in households: virus shedding without symptoms or antibody response. Am J Epidemiol 1987;126:506-515.

64. Elder AG, O'Donnell B, McCruden EA, Symington IS, Carman WF. Incidence and recall of influenza in a cohort of Glasgow healthcare workers during the 1993-4 epidemic: results of serum testing and questionnaire. BMJ 1996;313:1241-1242.

65. Occupational Safety \& Health Administration. Bloodborne Pathogens and Needlestick Prevention. Standard 1910.1030. Washington, DC: Occupational Safety \& Health Administration; 2003. Available at www.osha.gov/SLTC/bloodbornepathogens/standards.html. Accessed August 23, 2005.

66. Chance J, Williamson S. A user-friendly approach to improving healthcare worker influenza vaccination compliance. Am J Infect Control 2005;33:E62.

67. Trape-Cardoso M, Divinere M, Barnosky S. Improving compliance with influenza vaccination for hospital healthcare workers from highrisk areas: a 6-year analysis. Am I Infect Control 2005;33:E89.

68. Thomas DR, Winsted B, Koontz C. Improving neglected influenza 
vaccination among healthcare workers in long-term care. J Am Geriatr Soc 1993;41:928-930.

69. Ohrt CK, McKinney WP. Achieving compliance with influenza immunization of medical house staff and students: a randomized controlled trial. JAMA 1992;267:1377-1380.

70. Sartor C, Tissot-Dupont H, Zandotti C, Martin F, Roques P, Drancourt M. Use of a mobile cart influenza program for vaccination of hospital employees. Infect Control Hosp Epidemiol 2004;25:918-922.

71. Bryant KA, Stover B, Cain L, Levine GL, Siegel J, Jarvis WR. Improving influenza immunization rates among healthcare workers caring for high-risk pediatric patients. Infect Control Hosp Epidemiol 2004;25:912-917.

72. Centers for Disease Control and Prevention. Interventions to increase influenza vaccination of health-care workers: California and Minnesota. MMWR 2005;54:196-199.

73. Mahoney FJ, Stewart K, Hu H, Coleman P, Alter MJ. Progress toward the elimination of hepatitis B virus transmission among health care workers in the United States. Arch Intern Med 1997;157:2601-2605.

74. The Leapfrog Group. Leapfrog Hospital Quality and Safety Survey. Washington, DC: The Leapfrog Group; 2005. Available at www.leapfroggroup.org/for_hospitals. Accessed August 25, 2005.

75. Poland GA, Tosh P, Jacobson RM. Requiring influenza vaccination for health care workers: seven truths we must accept. Vaccine 2005;23:2251-2255.

76. Bearman G, Fuentes L, Van Vorenkamp JL, Drusin LM. Vaccination without documentation: influenza immunization among medical residents at a tertiary-care medical center. Infect Control Hosp Epidemiol 2003;24:626-628.

77. Cooper L, Rosenbaum P, Mackie K, Winkler A, Cosgrove SE, Perl TM. Respiratory etiquette, surveillance, and feedback: tools to manage respiratory illness in healthcare facilities. Presented at the 14 th Annual Meeting of the Society for Healthcare Epidemiology of America; April 9-12, 2005; Los Angeles, CA.

78. Centers for Disease Control and Prevention. Updated interim influenza vaccination recommendations: 2004-05 influenza season. MMWR 2004;53:1183-1184.

79. Centers for Disease Control and Prevention. Tiered use of inactivated influenza vaccine in the event of a vaccine shortage. MMWR 2005;54:749-750

80. Centers for Disease Control and Prevention. Update: influenza vaccine supply and recommendations for prioritization during the 200506 influenza season. MMWR 2005;54:850.

81. Manning A. Flu vaccine maker Chiron gets second dose of bad news. USA Today. July 21, 2005:D7.

82. Centers for Disease Control and Prevention. Updated recommendations from the Advisory Committee on Immunization Practices in response to delays in supply of influenza vaccine for the 2000-01 season. MMWR 2000;49:888-892.

83. Rajput V, Bekes CE. Ethical issues in hospital medicine. Med Clin North Am 2002;86:869-886.

84. Moser MR, Bender TR, Margolis HS, Noble GR, Kendal AP, Ritter DG. An outbreak of influenza aboard a commercial airliner. $A m J$ Epidemiol 1979;110:1-6.
85. Schulman JL. Experimental transmission of influenza virus infection in mice: IV. Relationship of transmissibility of different strains of virus and recovery of airborne virus in the environment of infector mice. J Exp Med 1967;125:479-488.

86. Schulman JL. The use of an animal model to study transmission of influenza virus infection. Am J Public Health Nations Health 1968;58:2092-2096.

87. Garner JS. Guideline for isolation precautions in hospitals: the Hospital Infection Control Practices Advisory Committee. Infect Control Hosp Epidemiol 1996;17:53-80.

88. Bridges CB, Kuehnert MJ, Hall CB. Transmission of influenza: implications for control in health care settings. Clin Infect Dis 2003;37:1094 1101.

89. Salgado CD, Farr BM, Hall KK, Hayden FG. Influenza in the acute hospital setting. Lancet Infect Dis 2002;2:145-155

90. Influenza Virus Vaccine, Live Intranasal FluMist [package insert]. Gaithersburg, MD: MedImmune Vaccines, Inc.; 2003.

91. Cosgrove SE, Fishman NO, Talbot TR, et al. Strategies for use of a limited influenza vaccine supply. JAMA 2005;293:229-232.

92. Talbot TR, Crocker DD, Peters J, et al. Duration of virus shedding after trivalent intranasal live attenuated influenza vaccination in adults. Infect Control Hosp Epidemiol 2005;26:494-500.

93. Cha TA, Kao K, Zhao J, Fast PE, Mendelman PM, Arvin A. Genotypic stability of cold-adapted influenza virus vaccine in an efficacy clinical trial. J Clin Microbiol 2000;38:839-845.

94. Vesikari T, Karvonen A, Korhonen T, et al. A randomized, doubleblind, placebo-controlled trial of the safety, transmissibility and phenotypic stability of a live, attenuated, cold-adapted influenza virus vaccine $(\mathrm{CAIV}-\mathrm{T})$ in children attending day care. Presented at the 41st Annual Interscience Conference on Antimicrobial Agents and Chemotherapy; December 16-19, 2001; Chicago, IL.

95. Tablan OC, Anderson LJ, Besser R, Bridges C, Hajjeh R. Guidelines for preventing health-care-associated pneumonia, 2003: recommendations of CDC and the Healthcare Infection Control Practices Advisory Committee. MMWR Recomm Rep 2004;53:1-36.

96. Centers for Disease Control and Prevention. Respiratory Hygiene/Cough Etiquette in Healthcare Settings. Atlanta, GA: Centers for Disease Control and Prevention; 2004. Available at www.cdc.gov/flu/professionals/ infectioncontrol/resphygiene.htm. Accessed August 26, 2005.

97. Treanor J, Keitel W, Belshe R, et al. Evaluation of a single dose of half strength inactivated influenza vaccine in healthy adults. Vaccine 2002;20:1099-1105.

98. Belshe RB, Newman FK, Cannon J, et al. Serum antibody responses after intradermal vaccination against influenza. $N$ Engl J Med 2004; 351:2286-2294.

99. Kenney RT, Frech SA, Muenz LR, Villar CP, Glenn GM. Dose sparing with intradermal injection of influenza vaccine. N Engl J Med 2004; 351:2295-2301.

100. Kroff T, Heckard R. Taking charge of the demand side when shortsupplied: prioritized distribution of the 2004-2005 influenza vaccine to members in common of a designated high-priority group of healthcare workers. Am J Infect Control 2005;33:E92. 